\title{
Observing sovereignty, law and politics at the global level
}

\author{
Jiři Přibáň, Sovereignty in Post-Sovereign Society: A Systems Theory of
}

\section{European Constitutionalism}

\section{Farnham: Ashgate/Routledge, 2015, pp. 254, ISBN 9781472460875 (hbk)}

As part of the fallout from the British EU referendum, any suggestion that sovereignty has no relevance in the $21^{\text {st }}$ century would be hard to justify. And, in light of the same example, any suggestion that sovereignty has a clear referent, either in terms of a form of power, or the consequences of the exercise of that power, is also suspect. As such Jiři Přibáň's book is a timely contribution to current debates on the relevance of sovereignty to our current society. As per its title, it promises to enlighten the reader on questions of sovereignty through the application of systems theory. As a systems theory approach to sovereignty, constitutionalism, and the relationship between law and power, one expects, and finds, that Přibán draws heavily on the works of Niklas Luhmann and Gunther Teubner. But his book is not simply an application, or even an extension, of their works. Přibáň wants to stake out his own approach to understanding the developments which can lead to the description of world society ${ }^{1}$ as 'post-sovereign'. In particular, whilst he embraces Luhmann's analysis of national constitutions as the structural coupling of law and politics, he is critical of Teubner's use of the term constitution to describe relations between law and social systems other

\footnotetext{
${ }^{1}$ We refer to 'world society' here in a colloquial way. However, our further references represent the significance of world society, since the advent of 'the modern world', to the outlook and understanding of systems theory; for those unfamiliar with this background, see Luhmann's short statement, 2012, 83-99, or his extensively utilized 1997 article.
} 
than politics. This criticism, which has also been made by others, ${ }^{2}$ is that there is something wrong, or at least something unproductive in terms of our understanding of society, if we look for constitutions within social relations that do not involve politics. Instead, he argues, we must continue to look for constitutions, at the national and transnational level (especially the EU), in terms of the structural coupling of law and politics. In a surprising twist, he also suggests that this search will be assisted through the supplementation of systems theory by using Foucault's analysis of the nature of modern power - seeing power as contingent and ubiquitous. Thus in this review essay we consider what is involved in a systems theory understanding of sovereignty; what this might add to our understanding of national constitutions; whether it is inappropriate to apply the term 'constitution' to structural coupling between law and social systems other than politics; whether one can combine a Foucaultian and systems theory analysis of the nature of political power in one's search for the evolving relationship between law and politics at the global and EU levels; how sovereignty remains as a crucial ingredient.

The claim that we now exist in a post-sovereign age is, to quote Mark Twain, 'greatly exaggerated'. Sovereignty has never been synonymous with effective political power, so the weaknesses of states' abilities to dictate their economic and financial policies or their levels of social welfare should not in itself lead us to dismiss the practical importance of power structured through the semantics of states, and the importance of sovereignty in organising

\footnotetext{
${ }^{2}$ Christodoulidis, 2011, for example, taking the example of societal constitutionalism within the economy asks: '... is it useful to grace the institutional facilitation of the all-too-predictable trajectories of capital accumulation with the term constitutional?' (241) See also Lindhal, 2011.
} 
communications by, and about, states, ${ }^{3}$ and even beyond states. States are major international actors and, despite the rise of monolithic multi-national corporations, are likely to remain the dominant international actors for the foreseeable future. But the consensus that leads to claims that we live in a 'post-sovereign' society is the belief, which is the subject of this essay, that there is something qualitatively different about what is happening at the global level in terms of politics, states and sovereignty compared with much of the rest of world society. ${ }^{4}$ Systems theory, with its focus on communication, gives us one way of observing this. Religion, science, and the economy are global systems of communication. Whatever the asymmetries of inclusion or exclusion from these systems that one finds in different parts of the globe, or within national territories, one cannot now (whether or not one ever could) plausibly describe them in terms of a medium that is structured by reference to actors that represent territories, who then in turn negotiate that medium between themselves. Trade blocs, and national economies, even before their weakening by the WTO regime and increased international trading, were never actors in the same manner as states. Science does not recognise national territory as having any relevance to itself, other than as an object to be observed (despite different cultural traditions there is no British science, Chinese science, etc). And our major religions are also worldwide. Whilst they may be structured around organisations whose membership is determined by reference to national territories, there is no distinct version of these religions which maps onto those territories - there is no British or American version of Catholicism,

\footnotetext{
${ }^{3}$ Statehood only recently became a global phenomenon especially in the context of post-colonialism. Those same post-colonial processes left the majority of the world's states weak, in the sense that their political structures operate alongside strong rival stratified and segmented ones: see Kjaer, 2011.

${ }^{4}$ Similar reflections to these about sovereignty are often made about the linked conception of 'constitutionalism', see essays in Dobner and Loughlin, 2010.
} 
or Islam (one of the reasons that so many of us struggle to make sense of the UK

Government's call to promote 'British values'). One can make similar observations about the mass media. Whilst there are undoubted features peculiar to the British press, and aspects of that press that focuses upon national forms of law and politics, media communications can also operate at a global level without any necessity to first organise themselves nationally and then communicate solely between national actors.

Thus whilst we may not live in a post-sovereign age, in the sense that so much of the political system still constructs itself on a national basis, and directs power through itself (with the assistance of law) on the same basis, we do live in what, using systems theory, can be described as a post-sovereign society. We live in a society that produces self-descriptions via its other social subsystems that describe itself (society) not in terms of nation states and their respective societies, but in many ways in terms of world society or other subdivisions of it (like transnationalism) that do not obviously rely on the discourse of sovereignty. The political system is no longer able plausibly to present the manner in which it has structured itself (nation states), as a meaningful self-description of society in general.

It is however difficult to equate this changing self-description with any definite empirical events. Whilst one can identify developments that have contributed to this change in what can be presented as society (economies are less embedded in national structures than previously, following the liberation of controls on the circulation of capital; the increased focus of science on problems of climate control has heightened awareness of the interconnectedness of our economies, etc.), a consideration of the non-territorial nature of much functional differentiation (for example, religion, science, education, and art) raises the 
question of how it ever came to be plausible, under conditions of functional differentiation, to understand societies in territorial terms. After all, the Catholic church organised itself in terms of a world community since its inception, trade has always been international, and science has never included territoriality within its operations - a scientific experiment does not change its meaning in response to the place in which it is conducted or the persons who carry out that experiment.

Whatever the changes that have led us here, a move to post-sovereign society is a move from a world in which it was plausible for the political system, which employed a semantics of sovereignty, to identify society with the territorially identified population/community which was subject to a particular sovereign, to a world where this is less plausible. The next question is what should happen next? How should we communicate about sovereignty under these new conditions?

There are, we would suggest, at least two levels of semantics that need to be kept separate if one is to be able to undertake this task. Let us call the first of these levels the empirical one. Despite accusations that systems theory (or at least Luhmann's version of it) ignores empirical evidence, the converse is actually true. As a sociological method, systems theory invites the observer to observe how systems construct themselves. Whilst the observer is never outside society, what is observed when one observes systems changes as those systems change. So, at the empirical level, we need to observe what is happening to the political system within this post-sovereign society. offers some convincing evidence of the continued substantive use of the semantics of sovereignty within the political and legal 
systems at both national and EU levels. Analysing the political and legal communications that led up to and followed the Maastricht Treaty, concludes:

As long as it continues to be used by politicians, activists, judges, lawyers and the public, sovereignty scarcely can be treated as just a redundant metaphor, a concept unrelated to the operations of the globalized politics and law. It continues to be a distinct self-referential conceptualization of specific legal and political problems of global, international, supranational (especially European) and constitutional law and politics and, therefore, remains part of the observation of, information about, and symbolic explanations of political and legal operations. ${ }^{5}(60)$

The next level of semantics deals with the semantics of theory. Which semantics should be used to observe on developments within a post-sovereign society? Systems theory invites us to understand constitutional sovereignty by utilising Luhmann's theory of world society as functionally differentiated into closed (autopoietic) subsystems, in which the constitution is not an objective entity, but a relationship ${ }^{6}$ generated separately from within law and politics. Law constructs the political constitution as the basis for identifying valid law, whilst politics constructs the legal constitution as the basis on which it can distribute power

\footnotetext{
${ }^{5}$ The recent British referendum result provides an obvious further example of the power of the semantics of sovereignty to motivate political action in the absence of any consensus as to what sovereignty represents, or what it can be used to achieve. Having re-asserted (taken back) British sovereignty by requiring that its delegation to the EU be revoked, the media now debate how and when it should be re-delegated (given away again) via new treaties with the EU, the Commonwealth, the USA, China, etc.

${ }^{6}$ Přibán̆ repeatedly calls it an organisation. In the loose sense of an 'arrangement' this is fine. But as systems theory locates organisations as systems that exist via membership and decisions, we have concerns about the constitution (as opposed to a Supreme Court) being called an organisation within a systems theory analysis.
} 
legitimately (with minimal risk of rejection). The relationship between the two is that of structural coupling where one system: 'presupposes certain features of its environment on an ongoing basis and relies on them structurally ... the forms of a structural coupling reduce and so facilitate influences of the [system's] environment on the system.' (Luhmann 2004, 382) The presupposing is mutual, leading to co-evolution. ${ }^{7}$

Přibáň shows us how systems theory can be used to examine theories of constitutionalism, and the future possibilities for constitutional sovereignty to develop at an empirical level. Chapter three is a good example of the former. Here he discusses the opposing theoretical accounts of constitutions offered by Carl Schmitt and Hans Kelsen. ${ }^{8}$ For Kelsen, constitutions retrospectively identify the community whose political power they constitute legally, so there cannot be a constituent power prior to the creation of the constitution. For Schmitt, a constitution cannot create political power, but only offer it the opportunity to be constituted legally. As such, that power not only precedes its legal expression in a constitution, but remains only provisionally expressed legally, since the constitution cannot remove the possibility that political force will be exercised extra-legally. Thus for Schmitt, the constituent political power is prior to the constituted power of the constitution, and remains available to act unconstitutionally. Přibáň shows how these classic attempts to theorise constitutions in terms of the primacy of either politics or law can be resolved by observing constitutions as the structural coupling of law and politics. Both theorists described systems that operate through self-reference. Both theorists rejected claims that

\footnotetext{
${ }^{7}$ For an historical account of this co-evolution within Western Europe from the $11^{\text {th }}$ century onwards, see Thornhill's seminal 2011 book.

${ }^{8}$ For a similar discussion of the paradoxical relationship between these theorists, but one less rooted in system theory, seeLindahl, 2007.
} 
politics (Schmitt) or law (Kelsen) were legitimised by the other, or by morality. Whilst neither theorist engaged with systems theory, Přibán̆ argues that their theories can be accommodated within this theoretical framework if one sees these respective claims of primacy, within politics and law, as the claims of heterarchical functionally differentiated systems. The claims made within these systems, examined singularly, are contradictory and temporally incoherent. But each system is supported in its self-reference by its internal reconstruction of the other within itself - structural coupling. Law offers technical precision to the definition of a political community via its construction of a political community which, within its communications, existed prior to the constitution, as well as a technically precise means to distribute power as administration. It does this via a reductionist reconstruction of politics as texts (such as constitutions and statutes). And in its adoption of constitutional forms, which can be recognised by law, politics gains an increased ability to harbour and distribute political power. But politics as a system is not reducible to texts, or what can be coded legal or illegal, either before, or after the introduction of a constitution.

So, where do we go next? If Luhmann's concept of structural coupling provides an adequate framework for observing on the formation and operation of constitutional sovereignty at the national level, what is the appropriate basis for observing on developments at the supranational or transnational level, particularly that of the EU? A number of moves are possible. Teubner's 'societal constitutionalism' (in particular 2012) ${ }^{9}$ adopts Luhmann's description of constitutions in terms of a structural coupling between law and politics with a view to examining the possibilities for structural couplings to operate, like political constitutions, but with law coupling with systems other than politics, particularly the

\footnotetext{
${ }^{9}$ Discussed at some length by Přibáň in Chapters four and five.
} 
economy. He calls these societal constitutions to distinguish them from political constitutions, and examines them not by reference to their ability to reproduce the structures of a political constitution (such as sovereignty and polity) but in terms of the dynamics of structural coupling. Do other systems seek secondary coding for their structures through law - with its technically precise normative (but not thereby necessarily moral) communications? Can this constituting utilisation of law lead to self-limitation? Can the structures self-referenced as fundamental within systems other than politics be internalised within law in terms of higher laws, laws that take precedence over other laws in the course of interpretation ('constitutional law')? Can these structural couplings lead to laws that selflimit systems in a manner similar to that performed by fundamental (now mainly expressed as 'human') rights within the political system?

For Přibáň societal constitutionalism is a wrong move. Not wrong because one cannot look for structural couplings between law and other social systems. Not wrong because one should not look for these couplings at the global level, as part of the study of transnational law. Not wrong empirically, as he accepts that there is evidence to support Teubner's claim that the dynamics of structural coupling are producing co-evolutions of law and social systems at a global level that have similarities to the historical co-evolution of law and politics which produced national constitutions. No, what is wrong is that one should not use the semantics of constitutionalism to describe these developments. And, a related objection, one should not neglect the study of politics in one's search for the possibilities of constitutions occurring at a supranational or transnational level. ${ }^{10}$

\footnotetext{
10 This essay does not deal with Přibáň's criticisms (115-116) of Teubner's suggestions that some forms of societal constitutionalism might offer protections to the cultures of indigenous people, many of which we
} 
We found the first of these objections puzzling. Pribáň is not one of those academics who believe that a 'correct' theoretical concept will have a major beneficial effect on the observed social phenomena, and an 'incorrect' one lead to a detriment, ${ }^{11}$ and in adopting this modest approach, he is being entirely consistent with systems theory since academic communication, which forms part of the systems of education and science, cannot be expected to be selected by other systems on any basis other than the operations, structures and redundancies of those other systems. ${ }^{12}$ And once this is conceded, what is the objection to Teubner's appropriation of the term 'constitutionalism' in his study of structural couplings? It may be true that Luhmann did not use this term in connection with any other structural coupling except that between law and politics. But systems theory should not, like some forms of Marxism, become a study in which the words of its principal author have a sacred quality. One might also object to this application of constitutionalism on the basis that it is mere metaphor. It will draw attention to features of society which strike the observer as similar to national constitutions, but without a theoretical basis for that identification. But this is not what Teubner is doing. He is not using a metaphor, but considering political constitutions as one example of a more general phenomenon. The label 'constitutionalism' draws attention to the similarities made apparent by the over-arching concept of structural coupling. One can see parallels between Teubner's theoretical move with constitutions, and Luhmann's response to claims that his own theory of autopoiesis, would agree with (see Nobles and Schiff 2012 at 292). Neither does it deal with many other aspects of Teubner's thesis of societal constitutionalism: see the Symposium (2013) 20(2) Indiana Journal of Global Legal Studies, and of particular relevance to Přibáň's focus on politics and power, Christodoulidis at 629-663; see also Nobles and Schiff 2013.

11 Přibáň expressly disavows this approach (e.g. at 49-50).

12 See also King, 2006 
previously developed by Maturana and Varela to explain biological evolution, was 'mere' metaphor. Luhmann sought to demonstrate that biological systems could be located within a general theory of systems that could include living systems, communicative systems, and cognitive systems. Having shown the general theory that linked these different systems, he did not regard it as inappropriate to take a term developed in the study of one of them, autopoiesis, and in keeping with his general theory of systems re-use it in the description of a different system. Teubner does something similar with his identification of constitutions as structural coupling, with his re-use of a term taken from one example of this concept to describe other examples.

Some of Přibáň's objections to societal constitutionalism amount to claims that Teubner, in his desire to identify societal constitutionalism, extends systems theory in a manner that contradicts its essential elements. For example, Přibán̆ subjects the following quotation to a number of criticisms.

$[\mathrm{N}]$ ot just politics, but other social systems, too, establish themselves through self-referential processes by which, ex nihilo, they constitute their own autonomy. Constitutions deal with the paradoxes of self-reference practically by externalizing them to the surrounding context. Social systems are never entirely autonomous: there are always points of heteronomy. If this externalization now occurs with the help of constitutions, the moment of heteronomy comes when the social system refers to the law. The 'self' of the social system is defined heteronomously by legal norms and it can define itself autonomously thereby ... 
its identity is created in its constitution through the re-entry of external legal descriptions into its own self-description. (Teubner 2012, 110)

\section{Criticism 1}

Contrary to Luhmann's concept of strict autopoietic normative and operative closure, Teubner continues in his early criticisms of Luhmann's concept of system autopoiesis [Law as an Autopoietic System 1993, 31] and reconceptualizes the autopoietic closure by linking it to the concept of social reflexivity, law as a hyper-cycle, intersystemic conflicts and so on. (110)

How is this observation germane to the issue here? The question of whether social systems can only be autopoietic or not (Luhmann) or can progress to an autopoietic state in stages (Teubner) does not seem relevant to how two admittedly autopoietic systems such as economy and law might co-evolve through structural coupling at the global level.

\section{Criticism 2}

[Teubner] suggests that legal normativity operates as an external description reentering the system's self-description. However, this legal normativity re-enters a specific functional system, such as the economy or education, exactly as normativity and not as external cognitive information to be appropriated by the autopoietic system's internal norms and operations. A societal constitution, therefore, is not structural coupling between the legal system and other social systems in its environment because, by definition, structural coupling 'is not a 
normative topic.' [Luhmann 2004, 385] It is heteronomy without any contribution to the social system's autopoiesis and/or co-evolution with other systems. Unlike the modern political constitution, it does not guarantee [our emphasis] the structural coupling of the legal and other social systems. [Luhmann 2004, 409-12] Societal constitutions only provide for help in the systemic self-reference by heteronomous legal definitions. (110)

Our suggested approach to making sense of what is involved in structural coupling, and whether societal constitutionalism is a misapplication of the term, is to start with the example on which Luhmann, Přibáň and Teubner all agree - a national constitution. Politics triggers its own second coding as law. Law provides a legal structure for political administration. Politics describes parts of itself in terms of these legal structures, but has to do so through communications that are linking via a different code (government/opposition) from the legal code (legal/illegal). Systems theory does not claim that the only system that can generate normative expectations is law, only that this is its particular contribution to the continuation of a highly complex society. So another system, such as politics, can have norms, and these norms can be second coded as legal norms. Thus, without claiming that the norms of law enter into another system, one can still recognise the manner in which legal norms might provide another system with something which it can reconstruct for itself as norms, rather than information about its environment. To sum this up, if we can agree on the dynamics of structural coupling between law and politics, and that this leads to the normative communications within the non-law system being second coded as legal, including the system's self-description as a state, then why is it contrary to autopoietic theory to look for similar developments arising via structural 
coupling between law and systems other than politics? Thus we read Teubner's passage as a re-statement of what occurs through structural coupling within politics and law, applied to different systems, rather than an attempt to re-articulate structural coupling as something outside the parameters of autopoietic theory. And we do not see this passage as a claim that structural coupling is a 'normative issue', either in the sense of being desirable, or in the sense that structural coupling itself replicates the meaning of any normative communications which form the coupling between two systems.

With this background concern we became puzzled by some of Přibáň's other criticisms of societal constitutionalism. For example, Teubner has argued that social systems other than politics may replicate aspects of the political system by having formal centres and spontaneous peripheries. Přibáň calls this 'retro-semantics' (113 and 115), by which he seems to mean that it replicates distinctions such as society/community utilised by earlier sociologists such as Tönnies, distinctions that have been displaced as appropriate descriptions of society by functional differentiation. ${ }^{13}$ But whilst an attempt to describe society as a whole in such terms might be an inappropriate harking back to something like medieval society, which self-organised both in terms of ranks, and spatially in terms of centres and peripheries, the same criticism cannot be made of the use of these kinds of distinctions in describing society's social subsystems. Without, we hope, committing the sin of treating Luhmann as a prophet, one can point to the example from Law as a Social

\footnotetext{
13 'The very distinction of the organization and spontaneous spheres is far from the process of functional differentiation due to its spatial/sectorial semantics and striking resemblance to the early modern sociological distinction of society and community (in which society was identified with high levels of professionalism, expertise and rational organization while community signified the process of spontaneous social evolution).'
} 
System chapter 7, which contains a description of the courts as the formal centre of the legal system, which interacts with a more spontaneous periphery where legal meanings can be more open, varied, and avoided - locating both contract and legislation within this periphery. The point here is that whilst the basal distinction of modern society is not organised by segmentation, or stratification, or centre/periphery, but functional differentiation, these other distinctions do not thereby disappear. They operate within a society constructed via the basal distinctions of functional differentiation, just as functional differentiation previously had to exist (in an enormously less complex form) within societies whose basal distinctions operated through segmentation, stratification, etc.

Another puzzling claim is that societal constitutions could not 'guarantee' the structural coupling between law and another system, 'unlike the modern political system'. But the modern constitution does not guarantee structural coupling - it is structural coupling. The closeness of this structural coupling was never guaranteed, nor can its continued closeness be guaranteed. The most one can say is that this structural coupling has resulted in a great many structures and related semantics, organising a great many operations, within both systems, such that a lot of redundancy would be lost if the coupling ceased. By contrast, the co-evolution of other systems with law, at least at the global level, is fragmentary, and may never develop the closeness and comprehensiveness of the political constitution. But whether it does or not is an empirical question that only the future will answer. ${ }^{14}$

\footnotetext{
14 Jiři Přibáň has responded to this criticism by saying that, by referring to a lack of 'guarantee', he meant: 'that organisations of societal constitutions are not structured as systems (Luhmann's concept of organisation is to be applied here) because they merely provide 'external assistance'. (Email to authors dated 12/5/16). Our criticism of his choice of words remains valid. With this intention, he seems to agree with our view that the
} 
We said earlier that Přibáň's 'related' objection to societal constitutionalism was that one should not neglect the study of politics in one's search for the possibilities of constitutions occurring at a transnational level. This forms the basis for his particular contribution to this debate. Having shown, especially in his discussion of Schmitt and Kelsen, how the structural coupling analysis can illuminate many of the difficulties of theorising constitutional sovereignty at the national level, he argues for the value of continuing to look for structural coupling between law and politics at the transnational level. In keeping with his dismissal of any suggestion that concepts developed within academia are likely to steer system operations, this is not a claim that a failure to look for politics will lead to less or wrong politics. It is a claim that the incentive to look for societal constitutionalism is the result of an erroneous assumption: the assumption that politics and law are not continuing to develop constitutions at the global level. Politics, and its structural coupling with law, are there if one knows how to look for them.

This is an ambitious claim. That there is a failure of law and politics to develop at the global level with anything like the complexity and comprehensiveness that they exhibit at the national level is both a consensus, and the motivation for many kinds of theorising which look for alternatives to constitutional sovereignty at the global level. Přibáň's own analysis of the EU shows the difficulties and more recently the failures of attempts to replace nation state sovereignty and national polities by a constitution based on governance and expertise. The structural coupling of politics and law at the national level is strong and close, and ability of fragments of societal constitutions to move from organisational constitutions to system constitutions is something that remains to be seen. 
motivates humans to communicate ${ }^{15}$ in these terms. Yet, alongside an analysis of the EU which makes it quite clear that national constitutionalism, the structural coupling of politics and law organised around territories, populations and states, is resilient and here to stay for some time, he urges us to look for the structural coupling of law and politics at the global level. This prompts the question, which Přibáň addresses especially in chapter five, of what we should be looking for.

Přibán invites us to look for the relationships between power and law at the global level. But what is meant here by power? He offers two ways to track power at the global level. First, he rejects the assumption that nation state sovereignty does not continue to distribute power at a global level. And here he is supported by those who argue that global social systems, including the economy, continue to seek support from international and regional forms of law created via the agency of sovereign states - extradition agreements, TRIPS, WTO, bi-lateral agreements, etc. Economic actors are not willing to abandon access to the power of states, even whilst they endeavour to circumvent many of the restrictions on their economic freedom. Societal constitutionalism should not cause us to overlook the continued importance of states in the relationship between politics, law and other social systems at the global level. ${ }^{16}$ But Přibáň's next move we find more difficult. Following the approach of Foucault, he argues that it is not enough to identify the formal structures of

\footnotetext{
${ }^{15}$ Strictly, from a systems theory perspective, it is only systems that communicate; humans are just motivated to make the signs, gestures, sounds and key strokes that systems construct as communications. It's just easier to state their involvement as 'humans communicate'.

16 'Such political support, however, does not transform the economic constitution into a part of the state constitution. It is only the instruments of state power which law uses, depoliticizes, and places at the disposal of the societal constitution' Teubner, 2011, 250.
} 
power, organised through states (which Foucault called juridical power). We must look also at capillary power:

Capillary power, by its definition, rules out the possibility of some constitutional containment and rule-based settlement. It signifies expansive societal power unbound by any rules, customs and regulatory regimes. It is a model of the power of extremity directly contrasted to the power based in the sovereignty of either monarchical or democratic right and judicial exercise. $(126)^{17}$

What, within systems theory, is 'power unbound by any rules, customs and regulatory regimes'? Let us consider the possibilities, starting with the nation state. Within the nation state, systems theory sees power as a medium distributed through communications that operate a code - government/opposition; only things that can be coded in this way or caught up with such coding fall within the system of politics. The operations of the political system determine what has been collectively decided, which is the platform for further decisions, and so on. In undertaking this kind of analysis, one would not treat disciplinary techniques such as politics, or power as micro, relational and everywhere. Instead, one would look at disciplines and techniques in terms of their social meaning, identifying the kinds of communications that organise their use and evolution - identifying them by reference to the systems which generate the communications specific to their use. For

\footnotetext{
${ }^{17}$ Teubner 2012 discusses capillary power, briefly, at page 86. In his case, the concept is used to describe the manner in which the evolution of societal constitutions might be expected to occur internally within systems, at a microscopic level, aided by external pressures. Přibáň criticises Teubner for not making greater use of the concept: Teubner 'never explores its political context and impact' (126).
} 
example, the technology of 'the examination' can be called power but, within systems theory, the communications surrounding the administration of school and university examinations would be better described as the operations of the education system. This is not to say that a theorist cannot observe the common nature of technologies across all of society (as Foucault does), it is just that one is not then observing how systems observe themselves.

In an analysis of the evolution and existence of power within a nation state, Přibán̆ states that:

Political power is then different from non-political power relationships evolving in modern society without legal codification and political institutionalization. Political power, therefore, needs to be analysed as an intrinsic part of the functionally differentiated political system and its background practices and operations including structural coupling with the system of positive law in modern society. (136)

Here he is acknowledging that what is often called power is not power when this term is restricted to a medium distributed by the political system via a code of government/opposition, or ruler/ruled. And analysis of power should not be restricted to what is distributed within the political system, including that which is organised through a structural coupling with law. But where within systems theory (Přibáň offers reference frame) does this leave non-political power, especially capillary power, power unbounded by rules, customs or regulatory regimes? 
If we are to analyse society in terms of functional differentiation using systems theory, it is difficult simultaneously to adopt a Foucaultian understanding of power. There are overlaps of course. Foucault invites us to move from an understanding of power in terms of sovereignty to seeing power as everywhere within society, structured not just through juridical and political structures, but through epistimes and regimes, disciplines and technologies, in which knowledge and practices reflexively reinforce one another. ${ }^{18}$ Systems theory invites us to take a similar heterarchical approach to how society organises human action through communication - looking to art, religion, the economy, health, science, and the mass media, as well as politics and law. So there is a common rejection of over-reliance on understanding society in terms of juridical forms of political power. ${ }^{19}$ But the alternatives offered thereafter are not easily reconciled with one another within the same analysis. Systems theory examines action and actors as semantic constructs within different systems, and locates what Foucaultian analysis would call regimes within those systems. Much of what a Foucaultian approach would call 'power' is accounted for within systems theory in terms of the acceptance of communications as the basis for further communications. With Foucault there can always be resistance to power. With systems theory there is always the possibility of rejection - but at a social cost. Contestation exists outside of the political system, but this is not treated within systems theory as general non-political power. Law has its politics, as does art, science, religion, etc. ${ }^{20}$ The point here is that these contestations are

\footnotetext{
18 'Between techniques of knowledge and strategies of power, there is no exteriority, even if they have specific roles and are linked together on the basis of their difference.' (Foucault 1978, 98)

${ }^{19}$ On this similarity, see Pottage 1998, especially at 15.

${ }^{20}$ For Teubner, the focus is on centres of self-reflection within social systems. These occur both within institutions and in the periphery of systems. He argues that such self-reflection (reflection on self-description)
} 
not identical to those occurring within the political system. To call all these contestations indiscriminately 'power' is to abandon the very orientation that Přibán̆ is arguing for as a means to the scrutiny of world society.

What then is capillary power? If one removes the manner in which systems organise the humans who have to orientate themselves through the meanings generated by social systems, and then remove the contestations of meaning that occurs within those systems, is what remains something that one could call capillary power; or is it simply the looser forms of communication located outside of the formal centres of social systems, what Luhmann and Teubner would call the periphery? In which case, is it better to call this non-political power, or to focus on the relationship between the centre and the periphery, the formal and the informal, which is what in many ways Teubner does with societal constitutionalism.

As well as studying society's subsystems, one can use systems theory to observe interactions - which commonly involve a combination of communications that echo (adopt the semantics of) social system communications. But interactions - face to face communications - are not unbounded..$^{21}$ Indeed, that is why it is possible to observe them. And one can also study organisations, which additionally bring communications that echo social system communications into a relationship with each other, through decisions that would not be possible within social subsystems. But these too are not unbounded.

is not limited to giving effect to functional imperatives, but can take a normative form which includes some recognition of the necessity for self-restraint. (See Teubner, 2011)

${ }^{21}$ Though one would have to agree that mutual accommodation that makes conversations possible, and observable, cannot adequately be described in terms of rules or customs. 
Organisations need rules about membership and decision in order to construct their own existence - their self-reference.

So what is left? Systems theory is not deterministic. It provides an explanation for the great reduction in the possibilities of meaning that at the same time make it possible for society constantly to increase in complexity. But there is an irreducible element of contingency in all communication - it is always a selection from possibilities. ${ }^{22}$ And there is also contingency in the manner in which selections alter the possibilities for further selections, including those that come to operate as structures, which offer new restraints to the possibilities of meaning (and new possibilities for meanings to be accepted). So we could, if we wished, call these inescapable elements capillary power. They are both bound and unbound by rules, customs and regimes. Bound in the sense that the possibilities of what can be meaningfully communicated are constructed through systems, unbound in the sense that there is still a selection to be made. But how can these exercises of 'capillary power' be observed within systems theory? And even more challenging, how can we observe these exercises of capillary power in order to construct an understanding of the possibilities for law and power to operate at the level of world society? Or is this no more than a request to 'wait and see' what happens?

The highly selective elements we have offered in this essay do not challenge Přibáň's thesis that sovereignty has not been displaced either in the semantics of nation states or that concerning supranational and transnational authorities. Rather, together with

\footnotetext{
22 'Complexity, in this sense, means being forced to select; being forced to select means contingency; and contingency means risk.' (Luhmann 1995, 25)
} 
constitutionalism, it continues to offer a nexus of semantics together with structural changes that are reflected in world society. However his building bricks for reconstituting this nexus have, in our opinion, been over-strained. This conclusion does not deny some of the pertinent critiques of Teubner's societal constitutionalism or Foucault's analysis of power everywhere that Přibáň expresses. But our sense is that these critiques divert him from looking for what he needs to look for in understanding how such a nexus is developing. On the other hand, to give him credit, Luhmann's systems theory is so much more powerful in exploring the evolution of how we got to where we are now, then in highlighting where we are going next. Přibáň might be right that, particularly in relation to his example of authority within the European Union, there is an unresolved and perhaps paradoxical set of semantics that are struggling to match its legitimacy with that of the nation states that are a party to it. That said, we do indeed seem to be on the cusp of potentially new or highly reconstituted semantics in which sovereignty, perhaps fragmented and pluralistic, might well reappear and play a significant role.

\section{References}

Christodoulidis E (2011) Of boundaries and "tipping points": a response to Gunther Teubner. Social and Legal Studies 20(2) 238-243

Christodoulidis E (2013) On the politics of societal constitutionalism. Indiana Journal of Global Legal Studies 20(2): 629-663

Dobner P and Loughlin M (2010) the Twilight of Constitutionalism? Oxford: Oxford University Press Foucault M (1978) The History of Sexuality: An Introduction. Harmondsworth: Penguin (original French edition 1976) 
King M (2006) What's the Use of Luhmann's Theory, in King M and Thornhill C, Luhmann on Law and Politics: Critical Appraisals and Applications. Oxford: Hart Publishing, chapter 2 Kjaer P (2011) The Concept of the Political in the Concept of Transnational Constitutionalism: A Sociological Perspective, in Joerges C (ed.) with Ralli T, After Globalisation - New Patterns of Conflict and their Sociological and Legal Reconstructions. Arena Report No 4/11, Centre for European Studies: University of Oslo, chapter 10 Lindahl, H (2007) Constituent Power and Reflexive Identity: Towards an Ontology of Collective Selfhood, in Loughlin M and Walker N (eds.) The Paradox of Constitutionalism: Constituent Power and Constitutional Form (Oxford: Oxford University Press) 9-24 Lindahl H (2011) Societal Constitutionalism as Political Constitutionalism: Reconsidering the Relation between Politics and Global Legal Orders. Social and Legal Studies 20(2) 230-237

Luhmann N (1995) Social Systems. Stanford: Stanford University Press (original German edition 1984)

Luhmann (1997) ‘Globalization or World Society: How to Conceive of Modern Society?’ International Review of Sociology 7(1): 67- 79

Luhmann N (2004) Law as a Social System. Oxford: Oxford University Press (original German edition 1993)

Luhmann N (2012) Theory of Society Volume 1. Stanford: Stanford University Press (original German edition 1997)

Nobles R and Schiff D (2012) Using Systems Theory to Study Legal Pluralism: What could be Gained? Law \& Society Review 46: 265-292

Nobles R and Schiff D (2013) Pulling Back from the Edge. Modern Law Review 76: 620-638

Pottage A (1998) Power as an art of contingency: Luhmann, Deleuze, Foucault. Economy and Society, $27(1): 1-27$

Teubner G (2011) Societal Constitutionalism Without Politics? A Rejoinder. Social and Legal Studies 20(2) 248-252 
Teubner G (2012) Constitutional Fragments: Societal Constitutionalism and Globalization. Oxford:

Oxford University Press

Thornhill C (2011) A Sociology of Constitutions: Constitutions and State Legitimacy in Historical-

Sociological Perspective. Cambridge: Cambridge University Press 